aware of these problems. Various approaches towards their amelioration have been suggested, including the following.

(a) For each training scheme to designate a trainee counsellor for consultation by trainees should they wish to discuss personal stress-related matters. Exactly who fulfils this role would vary from scheme to scheme. Some psychiatric tutors take this on themselves, though it is clear that this is far from universal practice. Indeed, many tutors believe that it is not appropriate for them to deal with such problems, and many trainees in turn worry that by revealing their problems to the tutor, they might be labelled as somehow "unstable" and have their career advancement prejudiced.

The CTC suggests that ideally the role should be filled by someone with appropriate training in counselling, who could be available at short notice, and who is idependent of the training centre itself. Trainees should know who this individual is, and the manner in which contact might confidentially be made. Of course, this is not to say that tutors or others involved with the training itself should refrain from taking on any counselling role. It will be up to individual trainees to consult who they will should they run into problems, but the availability of an independent counsellor can only serve to enhance the chances of trainees in trouble seeking appropriate and timely help.

(b) The support of peers should not be discounted. Fellow trainees are the only ones who really understand the stresses of individual schemes at any given time. They are therefore in many ways best placed to help trainees in trouble. Unfortunately, due to factors alluded to above, such peer support is often not terribly forthcoming. It is hoped that psychiatric tutors would take a lead in encouraging trainees to support each other. The election of a trainee representative should be encouraged, and he/she should see his/her role as facilitating support networks among trainees, as well as being the channel through which grievances can be aired. The election of trainee representatives to sit on various hospital committees, like the Division of Psychiatry and Training Committee, should also be encouraged. This would serve to facilitate flow of information from trainees to consultants and administrators, and give trainees experience in committee work. It would also enhance the role of trainees in decision making about broader issues of patient care.

(c) Regular meetings of trainees should be encouraged, and time allowed for trainees (expressly those in peripheral placements, who are often the most isolated) to attend such. Some training schemes organise regular groups for new intakes of SHOs/ registrars, usually facilitated by a psychotherapist. This is very useful to some trainees, and should at least be on offer.
Of course, these measures will only provide the framework in which the necessary support happens. Without them, however, it can only be anticipated that stressed trainees will continue to "go it alone", with potentially damaging consequences for themselves and for their patients.

DAVId CASTle,
Vice Chairman
Ola JunaID,
Chairman
RoB KeHOE,
Secretary
Collegiate Trainees' Committee

\section{Syllabus for MRCPsych Part 1}

\section{DeAR Sirs}

I am writing to express my concern over an apparent anomaly between the declared syllabus for the Part I examination for the College Membership and the questions set in the recent Part I examination in October 1991.

The syllabus states that: "in neuroanatomy the candidate's knowledge of the brain and spinal cord ... should be updated as the basis of neurological examination and diagnosis. The motor and sensory systems and the autonomic nervous system should be understood to the same level".

The authors of a book of multiple choice questions, Dr Puri and Dr Sklar, have interpreted these requirements as excluding the autonomy and physiology of the limbic system, primarily because these areas are specifically itemised in the Part II syllabus (personal communication).

Certainly, questions appeared in the paper set in October 1991 on both the anatomy and physiology of the limbic system.

I would be grateful for clarification of this matter.

Glan Rhyd and Pen-y-Fai Hospitals

Bridgend CF31 4LN

ROBERT COLGATE

\section{Reference}

PURI, B. K. \& SKLAR, J. (1990) Revision for the MRCPsych Part 1. Edinburgh: Churchill Livingstone.

\section{DEAR SIRS}

Thank you for letting me see the letter from Dr Colgate. The content for both Part I and Part II of the Examination are set out in the Regulations. Dr Colgate correctly quotes the Regulations which give the content in broad terms.

Unfortunately, it appears that Dr Colgate has accepted the interpretation given in the book to which he refers. The Examinations Office has never, to my knowledge, hitherto given more detailed information 